\title{
A web-based survey of contact lens-related adverse events among Japanese female population: Are decorative contact lenses dangerous?
}

Koichi Ono ( $\square$ kono@juntendo.ac.jp )

Juntendo University

Akira Murakami

Juntendo University

Yuji Haishima

National Institute of Health Sciences

\section{Research Article}

Keywords: Epidemiology, Decorative Contact Lenses, Complications, Japanese Females

Posted Date: February 26th, 2021

DOI: https://doi.org/10.21203/rs.3.rs-221310/v1

License: (c) (i) This work is licensed under a Creative Commons Attribution 4.0 International License.

Read Full License

Version of Record: A version of this preprint was published at Scientific Reports on August 5th, 2021. See the published version at https://doi.org/10.1038/s41598-021-95318-7. 


\section{Abstract}

\section{Objectives:}

To compare the frequency of contact lens $(\mathrm{CL})$-related complications and to identify the risk factors for transparent and decorative CL users.

\section{Methods:}

A web-based, cross-sectional, observational survey of adverse events related to $C L$ use was performed. The frequencies of complications were compared between two groups. Logistic regression analyses were performed to calculate an odds ratio (OR) for each metric. Age, replacement schedule, total experience, daily wear time, location of purchase, stacking of CLs, CL exchange with friends, compliance to hygiene procedure, replacement of CLs at intervals longer than recommended, and CL wear overnight were considered as confounders.

\section{Results:}

A total of 3,803 Japanese females were surveyed. The frequency of adverse events was $33.35 \%(95 \% \mathrm{Cl}$ : $31.27 \%-35.43 \%$ ) and $35.73 \%$ (95\% Cl: 33.53\%-37.98\%) for transparent and decorative CLs, respectively. In a multivariate model, statistically significant factors associated with complications included the following: quarterly schedule lenses, replacement of CLs at intervals longer than recommended, compliance to hygiene procedure, $\mathrm{CL}$ wear overnight, $\mathrm{CL}$ purchase at physical shops and on the internet, and longer daily wearing time.

\section{Conclusions:}

Most of the risk-increasing behaviors are preventable. The role of public health ophthalmology is to increase awareness and to improve CL use behaviors.

\section{Introduction}

Decorative contact lenses (DCLs) appeared in the USA in the early 1980s and were previously prescribed to mask eye flaws and improve the cosmetic appearance of the eye(s) [1]. Today, DCLs are fast becoming an essential fashion item, especially for young females. DCL wearers make up a significant and growing proportion of the contact lens (CL) wearing population in Asian countries [2].

The safety of cosmetic CLs is controversial. More specifically, there have been several negative reports about adverse events related to the use of DCLs [3-5].A recently published meta-analysis that was conducted by a manufacturing company about their own products summarized six, unpublished results regarding the safety of their DCLs and concluded that they were safe [6]. This report, as written, would be insufficient as a meta-analysis document because it did not provide the calculation of pooled odds ratios 
or relative risk assessment. In addition, the time periods considered in each of the studies were too short (1 week to 3 months) to effectively evaluate the safety of DCLs.

Review of existing literature revealed that some aspects in CL use behaviors were strongly associated with adverse events related to $C L$ use $[2,7,8]$. Regarding safety assessment in clinical trials, we surmise that during the clinical trial period, CL users would be uncharacteristically motivated to keep good hygiene behavior under the supervision of CL specialists. This behavior is in direct contrast to non-compliance reports that vary from $40 \%$ to $91 \%$ in real world settings [9-12]. The objectives of this study were to assess the safety of DCLs, and to investigate other independent risk factors of CL related complications for Japanese females of reproductive age through online survey methods.

\section{Methods}

Two sets of questionnaires were prepared by the survey team. The first was a screening test to recruit participants from internet users. The second was a detailed survey regarding the personal incidence of $\mathrm{CL}$ related eye complications, features of the CL purchase location, and personal CL use behaviors.

The preliminary screening survey included: age, sex, type of $C L$ in current use (DCL, transparent $C L$, or both), replacement schedule (daily, weekly, bi-weekly, monthly, quarterly, annually, or others/unknown), total experience with CLs (years), and daily wear time (hours). Subjects who met the inclusion criteria (i.e., Japanese females aged 16-49, routinely wearing soft CLs) immediately proceeded to next questionnaire. The subsequent survey asked about the location of CL purchase (physical shop, internet, or eye clinic/hospital), their personal experience of $\mathrm{CL}$ related eye problems in the previous year (yes or no), and their practice of the following behaviors: stacking CLs during wearing, exchanging CLs among friends, replacing CLs at longer intervals than recommended, sleeping while wearing CLs, and hygiene-related behaviors. To assess hygiene-related behavior, three questions were presented: 1) rinsing and/or preserving with tap water, 2) rinsing and/or preserving with expired disinfectant solution, 3) using the same $\mathrm{CL}$ case for more than three months.

The CL related eye complications were defined as the history of tearing, eye pain, and blurred vision. The web-based survey was conducted in November 2018 through a contract with a Japanese professional marketing research company (Cross Marketing Ltd.) that was experienced in many academic research studies.

\section{Statistical analyses}

Females who wore both DCLs and transparent CLs were considered within the DCL group. Regarding compliance to hygiene procedure, females who answered "Never" in all three hygiene-related questions were categorized as "good" compliance, while answers other than "Never" in any of the three hygienerelated questions were categorized as "bad" compliance. We used Student's t-tests for to assess differences among continuous data variables, and $\chi^{2}$ tests for categorical variables comparisons between two groups. 
Age, total experience with CLs, and daily wear time were treated as continuous variables, while the other variables from the surveys were treated as categorical. Simple and multivariate logistic regression analyses were performed to calculate crude and adjusted odds ratios (ORs) and $95 \%$ confidence intervals $(95 \% \mathrm{Cls})$ to assess the risk associated with adverse events related to $\mathrm{CL}$ use.

A $P$-value $<0.05$ in each statistical test for differences between population was accepted as significant. STATA SE/15.1 for Windows (STATA CORP LLC, Texas, USA) was used for statistical analyses.

\section{Ethical considerations}

The protocol of this study was approved by the Institutional Review Board of Juntendo University, School of Medicine, and the National Institute of Health Sciences. All participants provided informed consent electronically prior to commencing the survey. The study adhered to the tenets of the Helsinki Declaration.

\section{Results}

The screening test was distributed to 22,300 randomly selected, nationwide female panels aged 16-49 in accordance with the Japanese demographic structure. We received 8,508 responses. We distributed a detailed survey questionnaire to randomly selected 4,000 individuals. Those with an incomplete survey $(n=19)$, and surveys with an inconsistent response between screening test and second resurvey $(n=178)$ were excluded (Figure1). After exclusions, a total of 3,803 surveys were analyzed in this study (response rate: $95.1 \%)$.

The mean age \pm standard deviation of participants in this study was $28.70 \pm 7.73$ (Table 1). Tables 1 and 2 show the differences between the transparent and the decorative groups. Overall, $34.50 \%(95 \% \mathrm{Cl}$ : $32.99 \%-36.03 \%$ ) of the females surveyed experienced $\mathrm{CL}$ related eye problems in the previous year. The frequency of eye complication(s) was $33.35 \%$ (95\% Cl: $31.27 \%-35.43 \%)$, and $35.73 \%$ (95\% Cl:

$33.53 \%-37.98 \%$ ) for transparent and decorative group, respectively, and did not differ significantly between the $C L$ types $(p>0.05)$.

Crude and multivariate-adjusted ORs are shown in Table 3. Lens type was not associated with adverse events related to $C L$ use. Factors associated with an increase in $C L$ related eye complications include: quarterly replacement of $C L$ versus daily $C L$ replacement, longer daily wear duration, $C L$ purchase at physical shops and/or over the internet versus purchases at eye clinics/hospitals, poor compliance to recommended hygiene procedures, replacement of CLs at longer intervals than recommended, and sleeping in CLs.

\section{Discussion}

The research group of the Ministry of Health, Labor and Welfare, Japan, investigated the risk factors on CL-related eye problems among middle school and high school students throughout Japan. According to this survey [13], a higher school grade, and female sex as well as poor compliance with CL care were 
associated with the CL-related eye problems. Thus Just over 3,800 Japanese females aged 16-49 years were surveyed and those results were analyzed.

Our analysis revealed that there was no significant difference in the frequency of CL-related eye disorders between DCL and transparent CL groups. This result was contrary to our expectations as we expected there would be a different set of CL-related habits between the two groups. In fact, as Tables 2 and 3 show, the DCL wearers seemed to live a less risk-averse lifestyle regarding CL habits. In the multivariate analysis model, factors associated with increased frequency of eye complications included quarterly replacement schedule versus daily disposable use, longer wear times, purchases of CLs from shops and over the internet rather than from health professionals, poor compliance to hygiene procedures, extending the recommended $\mathrm{CL}$ replacement schedule, and the wearing of CLs while sleeping. A majority of the findings above are consistent with previous publications.

Replacement schedule is an important factor used to predict eye complication risk. In theory, the risk of adverse events related to $C L$ use for daily disposable CLs was less than any other type of CL. The decrease in risk associated with daily disposable CLs is attributed to the avoidance of CL solution interaction, $C L$ case contamination, and reduced likelihood of the introduction of biofilm to the CL or case. Despite these assumed benefits of disposable daily $\mathrm{CL}$, a significant difference was not observed between daily disposable CLs and other CLs. Our results showed similar safety or risk to other CLs when users behaved similarly. The reason of significantly higher OR for eye complication for quarterly CLs was unclear and should be investigated further. But considering a wide $95 \% \mathrm{Cl}$ of quarterly $\mathrm{CL}$ use amongst survey participants, a major reason might be due to the small number of them recruited in this study. Another confounding factor we did not consider was the potential that CL properties might be affected by other cosmetic item uses such as eyelash liners and/or hand creams that could result in eye damage.

Longer daily usage of CLs was associated with more eye complications in our analysis. The reason might be due to the potential that users with longer daily wear times included both extended wear CL users and overnight wearers. Corneal hypoxia due to longer CL usage makes the cornea vulnerable to infection [14]. Morgan et al.[15] described higher cumulative incidence rates of keratitis for extended CLs than for daily disposable CLs, regardless of lens materials used in manufacturing. Overnight CL wearing was also a well-known independent risk increase behavior $[16,17]$ and our result was consistent with those findings (OR: 1.27 [95\% Cl: 1.09-1.47]). In a biological sense, extended CL wear and overnight $\mathrm{CL}$ wear were associated with the presence of IL-8 and epidermal growth factor [18,19], both of which indicate mechanical trauma.

CL purchase by internet order [16] or at unlicensed vendor shops [20] were reported to increase the risks of adverse events because these purchase locales never provide eye examinations and/or sufficient counseling. Our results are consistent with these findings and we implore the need to improve health literacy for CL users. Regulation of purchase channels for CLs would be a considerable challenge for public health ophthalmology, but may reduce the incidence of adverse events related to CL use. 
Bacterial contamination of CLs or cases was associated with the onset of ocular infections and mainly resulted from tap-water exposure [21], use of expired CL solution, and poor CL case hygiene [22]. In line with these findings, we obtained a convincing result of higher ORs for "poor compliance to hygiene procedure". However, even greater ORs would likely be observed if we included more detailed hygienerelated behavior questions, such as, hand washing habits when handling CLs, personal practice of rubbing CLs, and/or the storage case after removing CLs.

Stacking one contact on top of another could change the fitting of $\mathrm{CL}$ and would reduce how much oxygen the cornea receives throughout the duration of $\mathrm{CL}$ wear. In our study, however, stacking behavior was not associated with CL-related eye complications. This result is likely due to relatively short wear time from either poor vision and/or discomfort. Exchanging CLs among friends was not related to adverse events, either. The reason for the lack of eye complication as a result of $\mathrm{CL}$ sharing might be due to the exchange a new pack of CLs with similar power and curve, or the friend wore the CLs for a short amount of time.

Age and total years of experience were not associated with a difference in rate of complications. The reason might be related to the correlation between age and experience. Regardless of the potential correlation, the significant relationship was not observed (results not shown) even when either experience or age was selected in multivariate logistic regression analysis. This result did not confer a greater level of the safety for experienced CL users and may be influenced by survival bias, meaning that only subjects who had no complications in the past with CLs, keep using CLs.

A major strength in this study was the large sample size that was recruited nationwide, in Japan. We do note that there were several limitations to this study. First, CL-related eye complications ranged from slight to severe, sight-threatening conditions. For this study, we considered all eye complications to be either present or not. Due to the survey aspect of this study, it would be not realistic to receive the information about medical diagnosis and severity from non-medical professionals, and may result in uncontrollable information bias. Second, we had no data on lens materials or CL brand for survey respondents. In our analysis, there was no significant difference in CL-related eye complications between transparent and DCLs. In general, those who participate in the health survey are said to have greater health literacy. These kinds of people might develop customer loyalty to brands that provide consistent, high-quality products. If counterfeit brands were on the market, the DCL wearing group, especially young females, might suffer disproportionately from eye injuries due to exposed pigments and surface roughness $[23,24]$ or from microbial contamination [25]. Third, we included confounding factors determined from our literature review. Confounders, such as, refraction, lens fitting, tobacco use, systemic disease, and socioeconomic status were not included. Due to the nature of online surveys, there might be a higher chance that some questions would be ignored or left unanswered. To avoid this bias, we selected only the most important questions.

Several studies indicated the higher risk of eye complications as a result of DCL use [3-5]. Our study found that there was no significant difference in adverse events related to CL use between the transparent $C L$ 
group and the DCL group. CL-related complications are preventable by improvement of CL user behaviors. All CL users should reduce daily wear time by avoiding overnight wearing and $C L$ users should maintain compliance to recommended hygiene procedures and lens disposable/replacement schedules under the supervision of eye health professionals. The findings from this research support the mission of public health ophthalmology that aims to create awareness of adverse events related to CL use, and to improve $\mathrm{CL}$ user behaviors to maintain their health and safety.

\section{Declarations}

\section{Acknowledgements}

This study was supported by the grants for Research on Regulatory Science of Pharmaceuticals and Medical Devices (18mk0102116h0501) from the Japan Agency for Medical Research and Development.

\section{Author Contributions}

K.O., A.M., and Y.H. conceptualized the project. K.O. performed all data analyses with input from A.M.. Y.H. supervised the project. K.O. drafted the manuscript. All authors read and approved the final manuscript.

\section{Additional information}

The authors declare no competing interests

\section{Data Availability Statement}

The data that support the findings of this study are available from the corresponding author, $\mathrm{KO}$, upon reasonable request.

\section{References}

[1] Berenson AB, Chang M, Hirth JM, Merkley KH. Use and misuse of cosmetic contact lenses among US adolescents in Southeast Texas. Adolesc Health Med Ther. 10, 1-6 (2019).

[2] Lim CHL, Stapleton F, Mehta JS. A review of cosmetic contact lens infections. EyelLond) 33, 78-86 (2019).

[3] Sauer A, Abry F, Berrod JP, Bron A, Burillon C, Chiquet C et al. Study and prevention of contact lensrelated microbial keratitis with a standardized questionnaire. J Fr Ophtalmo/33, 701-709 (2010).

[4] Singh S, Satani D, Patel A, Vhankade R. Colored cosmetic contact lenses: an unsafe trend in the younger generation. Cornea. 31, 777-779 (2012).

[5] Abdelkader A. Cosmetic soft contact lens associated ulcerative keratitis in southern Saudi Arabia. Middle East Afr J Ophthalmol. 21, 232-235 (2014). 
[6] Rah MJ, Schafer J, Zhang L, Chan O, Roy L. Barr JT. A meta-analysis of studies on cosmetically tinted soft contact lenses. Clin Ophthalmol. 7, 2037-2042 (2013).

[7] Lim CHL, Stapleton F, Mehta JS. Contact Lens-related Complications: A Review. J Ophthalmic Vis Res. 12, 193-204 (2017).

[8] Steele KR, Szczotka-Flynn L. Epidemiology of contact lens-induced infiltrates: an updated review. Clin Exp Optom. 100, 473-481 (2017).

[9] Wu Y, Carnt N, Stapleton F. Contact lens user profile, attitude and level of compliance to lens care. Cont Lens Anterior Eye. 33, 183-188 (2010).

[10] Claydon BE, Efron N. Non-compliance in contact lens wear. Ophthalmic Physiol Opt. 14, 356-364 (1994).

[11] de Oliveira PR, Temporini-Nastari ER, Ruiz Alves M, Kara-José N. Self-evaluation of contact lens wearing and care by college students and health care workers. Eye Contact Lens. 29, 164-167 (2003).

[12] Sokol JL, Mier MG, Bloom S, Asbell PA. A study of patient compliance in a contact lens-wearing population. CLAO J. 16, 209-213 (1990).

[13] Research on standard conformity of colored contact lenses (article in Japanese)

Preprint at https://dmd.nihs.go.jp/H26_color_contact/H26_research_report.pdf

[14] Hickson-Curran S, Chalmers RL, Riley C. Patient attitudes and behavior regarding hygirne and replacement of soft contact lenses and storage cases. Cont Lens Antrior Eye. 34, 207-215 (2011).

[15] Morgan PB, Efron N, Hill EA, Raynor MK, Whiting MA, Tullo AB. Incidence of keratitis of varying severity among contact lens wearers. Br J Ophtalmol. 89, 430-436 (2005).

[16] Stapleton F, Keay L, Edwards K, Naduvilath T, Dart JK, Brian G, et al. The incidence of contact lens related microbial keratitis in Australia. Ophthalmology 115, 1655-1662 (2008).

[17] Dart JK, Radford CF, Minassian D, Verma S, Stapleleton F. Risk factors for microbial keratitis with contemporary contact lenses: a case-control study. Ophthalmology. 115, 1647-54 (2008)

[18] Sack RA, Sathe S, Beaton A. Tear turnover and immune and inflammatory processes in the open-eye and closed-eye environments: relationship to extended wear contact lens use. Eye Contact Lens. 29, S8082 (2013).

[19] Kallinikos P, Morgan P, Efron N. Assessment of stromal keratocytes and tear film inflammatory mediators during extended wear of contact lenses. Cornea 25, 1- 10 (2006). 
[20] Steinemann TL, Pinninti U, Szczotka LB, Eiferman RA, Price FW Jr. Ocular complications assocoated with the use of cosmetic contact lenses from unlicenced vendors. Eye Contact Lens. 29, 196-200 (2003).

[21] Richdale K, Lam DY, Wagner H, Zimmerman AB Kinoshita BT, Chalmers R et al. Case-Control Pilot Study of Soft Contact Lens Wearers With Corneal Infiltrative Events and Healthy Controls. Invest Ophth Vis Sci. 57, 47-55 (2016).

[22] Ogushi Y, Eguchi H, Kuwahara T, hayabuchi N, Kawabata M. Molecular genetic investigations of contaminated contact lens storage cases as reservoirs of Pseudomonas aeruginosa keratitis. Jpn J Ophthalmol. 54, 550-554 (2010).

[23] Hotta F, Eguchi H, Imai S, Miyamoto T, Mitamura-Aizawa S, Mitamura Y. Scanning electron microscopy findings with energy-dispersive $\mathrm{x}$-ray investigation of cosmetically tinted contact lenses. Eye Contact Lens. 41, 291-296 (2015).

[24] Nomura Y, Toida H, Fukui C, Kai S, Nakaoka R, Kato R. et al. Evaluation of pigment distribution and depth analysis methods for decorative soft contact lenses. Eye Contact Lens. 44, S105-S112 (2018).

[25] Land AD, Penno KL, Brzezinski JL. Identification of Microorganisms Isolated From Counterfeit and Unapproved Decorative Contact Lenses. Forensic Sci. 63, 635-639 (2018)

\section{Tables}

Table1: Characteristic of studied population by lens type (Continuous variables)

\begin{tabular}{lcccc}
\hline & $\begin{array}{c}\text { All } \\
\square n=3,803)\end{array}$ & $\begin{array}{r}\text { Transparent CL } \\
\square n \llbracket 1,970 \square\end{array}$ & $\begin{array}{r}\text { Decorative CL } \\
(\mathrm{n}=1,833)\end{array}$ & $\begin{array}{c}\text { P-value } \\
(\square-\text {-test })\end{array}$ \\
\hline \hline Age & $28.70 \pm 7.73$ & $29.02 \pm 7.95$ & $28.36 \pm 7.48$ & 0.0084 \\
\hline $\begin{array}{l}\text { Total experience } \\
\text { (years) }\end{array}$ & $11.11 \pm 7.44$ & $11.42 \pm 7.78$ & $10.76 \pm 7.04$ & 0.0062 \\
\hline $\begin{array}{l}\text { Daily wear time } \\
\text { (hours) }\end{array}$ & $11.23 \pm 3.80$ & $11.73 \pm 3.64$ & $10.70 \pm 3.89$ & 0.0000 \\
\hline
\end{tabular}

CL: contact lens 
Table2: Characteristic of studied population by lens type (Categorical variables)

\begin{tabular}{|c|c|c|c|c|c|c|c|c|}
\hline & & \multicolumn{2}{|c|}{$\mathrm{ALL} \square \mathrm{n}=3,803)$} & \multicolumn{2}{|c|}{$\begin{array}{l}\text { Transparent } \\
\text { CL } \\
\square \mathrm{n} \square 1,970 \square\end{array}$} & \multicolumn{2}{|c|}{$\begin{array}{l}\text { Decorative } \\
\text { CL } \\
(n=1,833)\end{array}$} & \multirow[t]{2}{*}{$\begin{array}{l}\text { P-value } \\
\quad\left(\chi^{2-t e s t}\right.\end{array}$} \\
\hline & & $\mathrm{n}$ & $\%$ & $\mathrm{n}$ & $\%$ & $\mathrm{n}$ & $\%$ & \\
\hline \multirow[t]{6}{*}{ "Replacement schedule } & Daily & "1,985 & "52.20 & 895 & $4 \overline{45.43}$ & 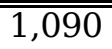 & "59.47 & 0.003 \\
\hline & Bi-weekly & 1,188 & 31.24 & 918 & 46.60 & 270 & 14.73 & \\
\hline & Monthly & 380 & 9.99 & 83 & 4.21 & 297 & 16.20 & \\
\hline & Quarterly & 36 & 0.95 & 5 & 0.25 & 31 & 1.69 & \\
\hline & One Year & 179 & 4.71 & 46 & 2.34 & 133 & 7.26 & \\
\hline & Others & 35 & 0.92 & 23 & 1.17 & 12 & 0.65 & \\
\hline \multirow[t]{3}{*}{ Location of purchase } & $\begin{array}{l}\text { Eye } \\
\text { clinic/hospital }\end{array}$ & 1,587 & 41.73 & 1,058 & 53.71 & 529 & 28.86 & 0.000 \\
\hline & Physical shop & 786 & 20.67 & 414 & 21.02 & 372 & 20.29 & \\
\hline & Internet & 1,430 & 37.60 & 498 & 25.28 & 932 & 50.85 & \\
\hline \multirow[t]{2}{*}{ Stacking of CLs } & No & 3,609 & 94.90 & 1,883 & 95.58 & 1,726 & 94.16 & 0.047 \\
\hline & Yes & 194 & 5.10 & 87 & 4.42 & 107 & 5.84 & \\
\hline \multirow[t]{2}{*}{$\begin{array}{l}\text { CL exchange with } \\
\text { friends }\end{array}$} & No & 3,647 & 95.90 & 1,903 & 96.60 & 1,744 & 95.14 & 0.024 \\
\hline & Yes & 156 & 4.10 & 67 & 3.40 & 89 & 4.86 & \\
\hline \multirow{2}{*}{$\begin{array}{l}\text { Compliance to hygiene } \\
\text { procedure }\end{array}$} & Good & 868 & 22.82 & 540 & 27.41 & 328 & 17.89 & 0.003 \\
\hline & Bad & 2,935 & 77.18 & 1,430 & 72.59 & 1,505 & 82.11 & \\
\hline \multirow{2}{*}{$\begin{array}{l}\text { Replacement of CL at } \\
\text { intervals longer than } \\
\text { recommended }\end{array}$} & No & 2,031 & 53.41 & 1,084 & 55.03 & 947 & 51.66 & 0.038 \\
\hline & Yes & 1,772 & 46.59 & 886 & 44.97 & 886 & 48.34 & \\
\hline \multirow[t]{2}{*}{ CL wear overnight } & No & 2,272 & 59.74 & 1,184 & 60.10 & 1,088 & 59.36 & 0.640 \\
\hline & Yes & 1,531 & 40.26 & 786 & 39.90 & 745 & 40.64 & \\
\hline
\end{tabular}


Table3: Factors associated with adverse events-related to CL use

\begin{tabular}{|c|c|c|c|c|c|c|c|c|c|}
\hline \multirow[t]{2}{*}{ Variables } & & \multirow{2}{*}{$\begin{array}{l}\text { Crude } \\
\text { ORs }\end{array}$} & \multicolumn{2}{|c|}{$95 \%$ CIs } & \multirow{2}{*}{$\begin{array}{c}p- \\
\text { values }\end{array}$} & \multirow{2}{*}{$\begin{array}{l}\text { Adjusted } \\
\text { ORs }\end{array}$} & \multicolumn{2}{|c|}{$95 \%$ CIs } & \multirow{2}{*}{$\begin{array}{c}p- \\
\text { values }\end{array}$} \\
\hline & & & $\begin{array}{l}\text { Lower } \\
\text { Limit }\end{array}$ & $\begin{array}{l}\text { Upper } \\
\text { Limit }\end{array}$ & & & $\begin{array}{l}\text { Lower } \\
\text { Limit }\end{array}$ & $\begin{array}{l}\text { Upper } \\
\text { Limit }\end{array}$ & \\
\hline \multirow[t]{2}{*}{ Lens type } & "Transparent & 1 & - & 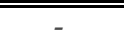 & 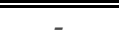 & 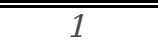 & 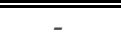 & 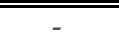 & 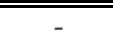 \\
\hline & Decorative & 1.11 & 0.97 & 1.27 & 0.122 & 0.96 & 0.83 & 1.12 & 0.631 \\
\hline \multirow[t]{6}{*}{ Replacement schedule } & Daily & 1 & - & - & - & 1 & - & - & - \\
\hline & Bi-weekly & 1.01 & 0.86 & 1.17 & 0.930 & 0.93 & 0.76 & 1.14 & 0.476 \\
\hline & Monthly & 1.38 & 1.10 & 1.73 & 0.005 & 1.28 & 1.00 & 1.65 & 0.054 \\
\hline & Quarterly & 2.26 & 1.17 & 4.38 & 0.016 & 2.22 & 1.12 & 4.40 & 0.022 \\
\hline & Annually & 1.36 & 0.99 & 1.86 & 0.054 & 1.33 & 0.95 & 1.86 & 0.096 \\
\hline & Others & 1.52 & 0.77 & 2.98 & 0.228 & 1.68 & 0.83 & 3.38 & 0.147 \\
\hline Age & (per year) & 0.98 & 0.97 & 0.99 & 0.000 & 0.99 & 0.98 & 1.01 & 0.380 \\
\hline Total experience & (per year) & 0.99 & 0.98 & 0.998 & 0.018 & 1.00 & 0.98 & 1.01 & 0.615 \\
\hline Daily wear time & (per hour) & 1.05 & 1.03 & 1.07 & 0.000 & 1.03 & 1.01 & 1.05 & 0.001 \\
\hline \multirow[t]{3}{*}{ Location of purchase } & $\begin{array}{l}\text { Eye } \\
\text { clinic/hospital }\end{array}$ & 1 & - & - & - & 1 & - & - & - \\
\hline & Physical shop & 1.36 & 1.13 & 1.62 & 0.001 & 1.28 & 1.06 & 1.54 & 0.010 \\
\hline & Internet & 1.31 & 1.13 & 1.52 & 0.000 & 1.23 & 1.05 & 1.45 & 0.013 \\
\hline \multirow[t]{2}{*}{ Stacking of CLs } & No & 1 & - & - & - & 1 & - & - & - \\
\hline & Yes & 1.24 & 0.92 & 1.66 & 0.160 & 0.97 & 0.66 & 1.43 & 0.872 \\
\hline \multirow[t]{2}{*}{ CL exchange with friends } & No & 1 & - & - & - & 1 & - & - & - \\
\hline & Yes & 1.19 & 1.02 & 1.40 & 0.032 & 1.01 & 0.65 & 1.56 & 0.973 \\
\hline \multirow[t]{2}{*}{$\begin{array}{l}\text { Compliance to hygiene } \\
\text { procedure }\end{array}$} & Good & 1 & - & - & - & 1 & - & - & - \\
\hline & Bad & 1.57 & 1.32 & 1.87 & 0.000 & 1.29 & 1.06 & 1.58 & 0.013 \\
\hline \multirow{2}{*}{$\begin{array}{l}\text { Replacement of CL at } \\
\text { intervals longer than } \\
\text { recommended }\end{array}$} & No & 1 & - & - & - & 1 & - & - & - \\
\hline & Yes & 1.76 & 1.54 & 2.02 & 0.000 & 1.59 & 1.37 & 1.86 & 0.000 \\
\hline \multirow[t]{2}{*}{ CL wear overnight } & No & 1 & - & - & - & 1 & - & - & - \\
\hline & Yes & 1.55 & 1.36 & 1.78 & 0.000 & 1.27 & 1.09 & 1.47 & 0.002 \\
\hline
\end{tabular}

CI: confidence interval

OR: odds ratio

CL: contact lens

\section{Figures}




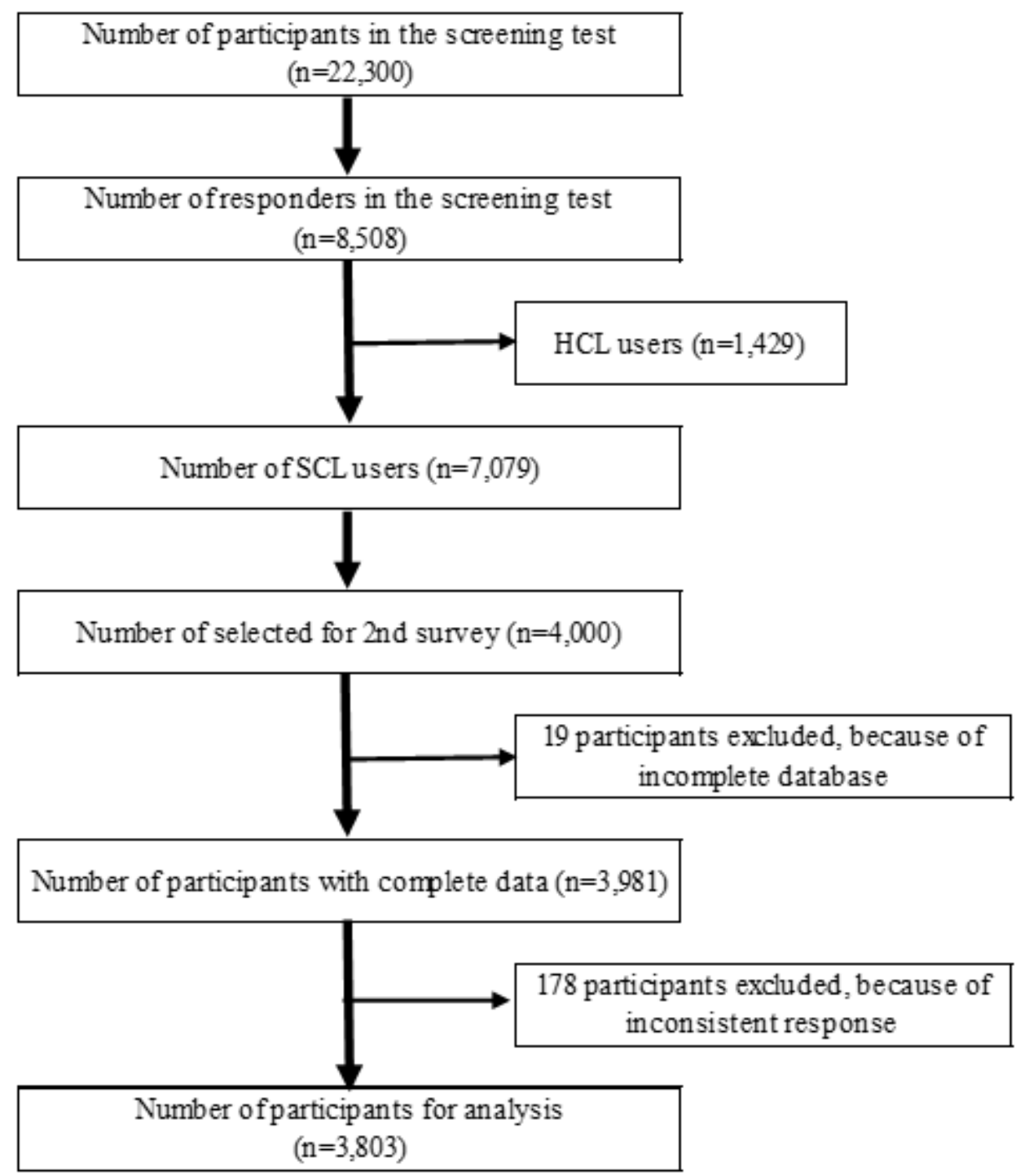

\section{Figure 1}

Flow diagram of study participants HCL: Hard contact lens, SCL: Soft contact lens 